\title{
GENOTYPIC VARIATION OF SOME EGYPTIAN AND UPLAND RICE GENOTYPES IN SOME PHYSIO- MORPHOLOGICAL TRAITS AND MICROSATELLITE DNA UNDER DROUGHT CONDITION.
}

Sedeek, S. E. M. ' T. F. Metwally'; Kazutoshi Okuno $^{2}$ and A. F. Abdelkhalik ${ }^{1}$

1.Rice Research \& Training Center, 33717 Sakha, Kafr EL-Sheikh, Field Crops Research Institute, Agricultural Research Center, Egypt.

2. Lab of plant Genetics and Breeding Science Graduate School of Life and Environmental Sciences, University of Tsukuba,305-8572 Japan

\begin{abstract}
Drought is a major constraint to the productivity of rice in the worldwide. The rice root system plays an important role in the regulation of water uptake and extraction from the deep soil layers. The objectives of this investigation were to study the variation in root morphology, some physiological traits, yield and its components and genetic diversity among some Egyptian rice varieties and some upland rice accessions under normal and drought conditions. Four upland rice accessions originated from Cote de Ivoire (IRAT112, IRAT170, WAB450-I-B-P-105-HB and Yun Len62) compared with three Egyptian rice varieties (Giza177, Sakha101 and GZ745613-6-5-3) were used in this investigation. Significant variation was observed in most of the investigated root traits such as root length, root volume, root thickness and root dry weight among the upland rice accessions and Egyptian rice varieties. Also there are a significant variation in some physiological traits which were related to fitness and productivity, including yield and its components under normal and drought conditions. This indicated that the upland rice accessions are tolerant to drought via its have good root system compared with the Egyptian rice varieties which were sensitive to drought. Most of the traits showed significant and highly significant correlation. Genetic diversity among the Egyptian rice varieties and upland rice accessions was studied with microsatellite markers. One hundred and forty alleles were detected with 80 SSR markers among all the rice accessions. The highest genetic relationship as revealed by SSR markers was detected among Giza 177, Sakha 101 and GZ7456-136-5-3 as japonica type, on the other hand there were some similarity between Egyptian rice varieties and each of WAB450-I-B-P-105-HB and Yun Len62. While, the lowest similarity was found among the Egyptian rice varieties and upland rice accessions IRAT 112 and IRAT 170 as indica type. Two dendrograms have been created based on 80 DNA markers (SSR primers) and 17physiologcal traits data for seven accessions and compared. Cluster analysis grouped the rice genotypes into three classes in which japonica type, Giza177, Sakha101 and GZ7456-13-6-5-3 in group1, meanwhile, WAB450-I-B-P-105-HB and Ynlen62 clustered in group 2. On the other hand IRAT112 and IRAT170 were clustered together as indica type in group 3. Based on this investigation the larger range of similarity values among varieties using microsatellites provides greater confidence for the assessment of genetic diversity and relationships.
\end{abstract}

Keywords: Rice, Drought, Physiological Traits, DNA Micorstallite.

\section{INTRODUCTION}

Water deficit (commonly known as drought) could be defined as the absence of adequate moisture necessary for a plant to grow normally and complete its life cycle. Rice (Oryza sativa $L$.) is one of the most important 
food crops in the world, since it is considered as the common food for more than $50 \%$ of the world population (Khush, 2005). Drought is one of the major constrains that affect on rice production worldwide. Development of rice varieties tolerant to drought is the most straightforward way to overcome water scarce problem. Although the conventional breeding programs has some success, still their is a big gap in understanding and manipulating such quantitative traits because this traits are a complex phenomena comprising a number of physio-biochemical processes at both cellular and organism levels at different stages of plant development (Tripathy et al. 2001). Drought resistance includes drought escape via short life cycle, drought avoidance via enhanced water uptake and reduced water loss and drought tolerance via osmotic adjustment and cell membrane stability. Breeding programs on rice drought resistance have relied on the plants ability to avoid water stress through vigorous water uptake from the soil, (Nemoto et al. 1998). This ability, referred to as drought avoidance, depends primarily on a rich underground root system with deep-elongated crown roots(Lilley and Fukai 1994,Kato et al. 2007 and Siopongco et al. 2005). Today, the genetics of root characters such as the depth of root system, ability of root penetration into hard pan, etc, involved in drought avoidance have been investigated extensively (Zhang et al. 2001, Kamoshita et al. 2002 and Zheng et al. 2003).Plant physiologists have long been aware that certain plants could maintain high biomass production even when they suffer internal water stress in the absence of drought avoidance (Ludlow and Muchow, 1990). This ability called drought tolerance (Fukai and Cooper, 1995) includes many underlying physiological processes (Zhang et al., 1999), such as osmotic adjustment that have been analyzed genetically (Lilley et al. 1996 and Robin et al., 2003). Nevertheless, the knowledge about the genetic control of drought tolerance, particularly at the whole plants level is still limited compared with that of drought avoidance. In fact, no previous breeding program has successfully utilized drought tolerance to improve rice dry matter production under drought (Fukai and Cooper, 1995 and Nguyen et al. 1997). However use of molecular markers provides a potentially effective selection technique for crop improvement and has advantages over selection based on phenotype (Tanksley et al. 1989 and Paterson et al. 1991). Simple Sequence Repeat (i.e. SSR or microsatellites) markers are very good genetic markers for genetic diversity studies in a wide range of plants, because of their high polymorphism, abundance and codominant inheritance, they are well suited for the assessment of genetic diversity within crop species and study the genetic relationships among species (Gupta et al.,1996, Wunsch and Hormaza, 2002).Understanding the physiological bases for drought to some of the Egyptian rice varieties will help the Egyptian rice program to start a more accurate research for developing new rice lines for the future over coming the problem of water shortage in Egypt.

Thus the main objectives of this work were to evaluate some Egyptian rice varieties and exotic under drought stress, study the physiological traits that known to be correlated with drought tolerance and evaluated genetic variation for root morphology, physiological traits and yield and its components in some Egyptian rice varieties and upland rice 
accessions and finally the examination of the genetic relations among these genotypes, in particular comparison of results from SSR markers with their known pedigrees.

\section{MATERIALS AND METHODS}

\section{Plant materials and drought stress treatment}

Seven rice varieties including three Egyptian rice varieties namely: Giza 177, Sakha 101 and GZ7456-13-6-5-3 japonica type (lowland rice) and four varieties namely IRAT 112, IRAT170, WAB450-I-B-P-105-HB and Yun Len62 (upland rice) developed in Cote de Ivoire. The experiment was laid out with six replications in a randomized complete blocks design for each of the control and drought stress. Rice plants were grown in PVC pipes, one plant per pipe. The pipe was $20 \mathrm{~cm}$ in diameter and $50 \mathrm{~cm}$ in length with holes on two sides at 25 and $50 \mathrm{~cm}$ from the top. Each pipe was filled with organic soil; the fertilizers were applied as $4 \mathrm{~g}$ from $\mathrm{N}, \mathrm{P}_{2} \mathrm{O}_{5}$ and $\mathrm{K}_{2} \mathrm{O}$ per pipe in greenhouse of Plant Genetics and Breeding Science, Graduate School of Life and Environmental Sciences, University of Tsukuba, Japan .All rice varieties were sown on $7^{\text {th }}$ May,2008, two germinated seeds were directly sown in each pipe and only one healthy plant was kept at 30 days after sowing. At the beginning of the tillering stage, $1 \mathrm{~g}$ of urea (dissolved in water) was applied to each pipe. The plants were fully irrigated by watering every day until the drought treatment. Drought stress was applied to six of blocks (flash irrigation every twenty days without any standing water) three of them for measurement the root traits after 45 days from sowing and the other three for measurement the physiological traits and yield and its components at heading and harvesting. While, the other six blocks were used as control (continuous flooding), three of them for measurement the root traits after 45 days from sowing and the other three for measurement of physiological traits and yield and its components at heading and harvesting.

Traits and measurements: A total of 17 traits were recorded in this study, 12 of them were collected from the above ground parts of the plants and the other five were root traits.

The traits which collected from above ground parts were related to fitness and productivity, including yield and its components traits which were examined for all varieties under control and stress conditions, including grain yield plant ${ }^{-1}(\mathrm{~g})$, panicles plant ${ }^{-1}, 1000$-grain weight $(\mathrm{g})$, filled grains panicle ${ }^{-1}$, and panicle length. In addition, two traits related to the water status of the plants, leaf drying score and number of days to leaf rolling, were also recorded. Leaf drying score was recorded on the basis of the degrees of leaf drying immediately after re-watering as 0 (no leaf drying) to $4(20 \%$ of leaf area was drying), number of days to leaf rolling of each plants was recorded as the number of days from application of drought stress to the day when all leaves become rolled at noon.

The root traits were scored after 45 days from sowing, maximum root length $(\mathrm{cm})$ was measured from shoot base to the tip of the longest roots, root volume (in milliters) was measured in a cylinder using the water replacing method (Price and Tomos 1997), root thickness (in millimeter), of 
five random roots was measured at $2 \mathrm{~cm}$ from the shoot base using micrometer, root dry weight (grams), shoot dry weight (grams) and root/shoot ratio were recorded after dried the samples in oven. Also, the other physiological traits such as plant height $(\mathrm{cm})$ was measured from the soil surface to the tip of longest panicle, days to heading (days) and flag leaf area $(\mathrm{cm})$ were measured.

\section{Statistical analysis:}

The mean data of seven varieties for all the characters under both each of water stress and fully irrigation condition were subjected to analysis of variance according to the differences between means were tested using the LSD method.

\section{DNA isolation:}

Genomic DNA was isolated from the leaves of the rice genotypes using CTAB method described by Murray and Thompson 1980, with minor modification. DNA was extracted by $1 \%$ Cetyltrimethylammonium bromide (CTAB) solution in $200 \mathrm{mM}$ Tris, $250 \mathrm{mM} \mathrm{Nacl}, 25 \mathrm{mM}$ EDTA and $0.5 \%$ SDS. The crude DNA obtained was dissolved in $100 \mathrm{ml}$ of TE buffer after purification.

\section{SSR analysis}

A total of 154 SSR primers were screened and 80 primers were selected on the basis of clear and polymorphic banding pattern among the genotypes. The PCR reaction mix includes the following DNA, $0.5 \mathrm{ml}, 2 \mathrm{ml} 10$ $\mathrm{x}$ buffers, $1 \mathrm{ml}$ dNTPs, Mgcl2, $0.25 \mathrm{ml}$ each of forward and reverse primers. The PCR profile start with $94 \mathrm{c}^{\circ}$ for $5 \mathrm{~min}$ followed by 35 cycles of denaturation at $94 \mathrm{c}^{\circ}$ for $30 \mathrm{sec}$, annealing at $55 \mathrm{c}^{\circ}$ for $30 \mathrm{sec}$, extension at $72 \mathrm{c}^{\circ}$ for $30 \mathrm{sec}$. A final extension was kept $7 \mathrm{~min}$ at $72 \mathrm{c}^{\circ}$ then on $4 \mathrm{c}^{\circ}$. The PCR products were subjected to a electrophoresis using $10 \%$ of polyacrylamide gel. After electrophoresis gels were stained with Eithdium bromide.

\section{Data analysis:}

All genotypes were scored for the presence and absent of the SSR bands and the data were entered into a binary matrix as discrete variables, 1 for presence and 0 for absence of the character and this data matrix was subjected to further analysis. The Excel file containing the binary data was imported into NT Edit of NTSYS-PC 2.02j.The 1/0 matrix was used to calculate similarity as DICE coefficient using SIMQUAL subroutine in similarity routine. The results similarity matrix was employed to construct dendrogrons using Sequential Agglomerative Hierachical Nesting (SAHN) based UN weighted pair Group Method with Arithmetic means (UPGMA, according to Rohlf, 2000). to infer genetic relationships and phylogeny in addition to principal components analysis based clustering was also done using the subroutine ELGEN. Genetic similarities among the genotypes were determined on the basis of Dice coefficient (Dice, 1945, Nei and Li, 1979). The different variance components of the varieties traits under study were calculated and used to estimate the genetic portions of variation. Heritability percentage was computed on a plot basis as the ratio of genotypic variance and phenotypic, genotypic coefficients of variability and phenotypic coefficients of variability were estimated according to the method suggested 
by Burton (1952) and Allard (1960), the expected genetic advance from selection for all traits was estimated according to Gamble (1962).

\section{RESULTS AND DISCUSSION}

\section{Variation in root morphology:}

It has been suggested that root traits, particularly maximum root length (MRL), root volume (RV), root thickness (RT), root dry weight (RW), shoot dry weight (SW) and root shoot ratio are more important for drought resistance in rice. In this study, some physiological traits such as days to leaf rolling, leaf drying score, flag leaf area, days to heading and plant height were also recorded under folding irrigation and drought treatment, in addition to yield and its components.

Regarding to root morphology, significant variation in all the investigated traits were found indicating the presence of high genetic diversity among the upland rice accessions ( IRAT 112, IRAT 170, WAB450-I-B-P105-HB and Yun Len62) and the Egyptian rice verities (Giza 177, Sakha 101 and GZ7456-13-6-5-3) under normal and drought conditions. The four upland rice accessions recorded the highest values of root traits compared with the Egyptian varieties, for example, WAB450-I-B-P-105-HB gave the highest maximum root length and root volume $(36 \mathrm{~cm}$ and 56 milliliter) while, GZ7456-13-6-5-3 gave the lowest values (17.6cm and 24 milliliter) under drought treatment. WAB450-I-B-P-105-HB and IRAT 112 upland rice accessions have thicker roots with a diameter 1.2 and $1.1 \mathrm{~mm}$, while, Giza 177, Sakha 101 and GZ7456-13-6-5-3 gave the lowest values of 0.5, 0.7 and $0.6 \mathrm{~mm}$, respectively. WAB450-I-B-P-105-HB and IRAT 112 recorded the highest values of root dry weight 5.2 and 5.1 gram respectively while, the lowland rice varieties Giza 177; Sakha 101 and GZ7456-13-6-5-3 recorded the lowest values 2.9, 3.0 and 2.7 gram respectively under drought treatment, also under normal condition. Concerning to root/shoot ratio WAB450-I-B-P$105-\mathrm{HB}$ gave the highest ratio 0.623 compared with the other genotypes.

Table 1. Means for root morphology and shoot dry weight traits of some Egyptian and upland rice accessions at $\mathbf{4 5}$ days.

\begin{tabular}{|c|c|c|c|c|c|c|}
\hline \multirow[t]{2}{*}{ Entry } & \multicolumn{2}{|c|}{$\begin{array}{c}\text { Root Length (RL) } \\
(\mathrm{cm})\end{array}$} & \multicolumn{2}{|c|}{$\begin{array}{c}\text { Root Volume (RV) } \\
\text { mll }\end{array}$} & \multicolumn{2}{|c|}{$\begin{array}{l}\text { Root Thickness } \\
\text { (RT)(mm) }\end{array}$} \\
\hline & Control & Drought & Control & Drought & Control & Drought \\
\hline \multirow{8}{*}{$\begin{array}{l}\text { Giza177 } \\
\text { Sakha101 } \\
\text { GZ7456 } \\
\text { IRAT112 } \\
\text { IRAT170 } \\
\text { WAB450 } \\
\text { Yun Len62 } \\
\text { LS.D.0.05 }\end{array}$} & 28.3 & 21.0 & 43.0 & 25.6 & 0.5 & 0.5 \\
\hline & 31.0 & 21.7 & 44.0 & 27.0 & 0.6 & 0.7 \\
\hline & 25.0 & 17.6 & 39.0 & 24.0 & 0.5 & 0.6 \\
\hline & 44.6 & 34.0 & 55.3 & 46.7 & 1.1 & 1.1 \\
\hline & 41.0 & 31.0 & 51.6 & 42.3 & 1.0 & 1.0 \\
\hline & 47.0 & 36.0 & 66.6 & 56.0 & 1.2 & 1.2 \\
\hline & 42.0 & 28.7 & 56.6 & 38.7 & 0.9 & 0.9 \\
\hline & 1.83 & 1.75 & & 3.64 & 0.13 & 0.14 \\
\hline \multirow{2}{*}{ Entry } & \multicolumn{2}{|c|}{$\begin{array}{l}\text { Root Dry weight } \\
(\text { RDW })(g)\end{array}$} & \multicolumn{2}{|c|}{ Root/Shoot Ratio } & \multicolumn{2}{|c|}{$\begin{array}{c}\text { Shoot Dry Weight } \\
\text { (gm) }\end{array}$} \\
\hline & Control & Drought & Control & Drought & Control & Drought \\
\hline Giza177 & 5.0 & 2.9 & 0.226 & 0.533 & 21.83 & 5.43 \\
\hline Sakha101 & 5.4 & 3.0 & 0.200 & 0.397 & 26.27 & 7.67 \\
\hline GZ7456 & 4.3 & 2.7 & 0.166 & 0.467 & 25.13 & 6.00 \\
\hline IRAT112 & 6.2 & 5.1 & 0.123 & 0.553 & 50.93 & 9.27 \\
\hline IRA & 5.7 & 4.5 & 0.117 & 0.337 & 47.77 & 13.33 \\
\hline & 6.7 & & 0.116 & 0.623 & 58.43 & 8.33 \\
\hline n62 & 6.5 & & & 0.493 & 61.37 & 9.00 \\
\hline LS.D & 0.56 & 1.13 & & & 4.63 & 1.60 \\
\hline
\end{tabular}


The results revealed that there are many upland rice accessions originated from Cote Ivoire (IRAT 112, IRAT 170, WAB450-I-B-P-105-HB and Yun Len62) with favorable root characteristics such as high maximum root length, root volume, root thickness, root dry weight and root/shoot ratio which positively contribute to drought avoidance in rice through increase water uptake from soil, therefore could use these genotypes as a donor in breeding program to improve drought traits in Egyptian rice varieties.

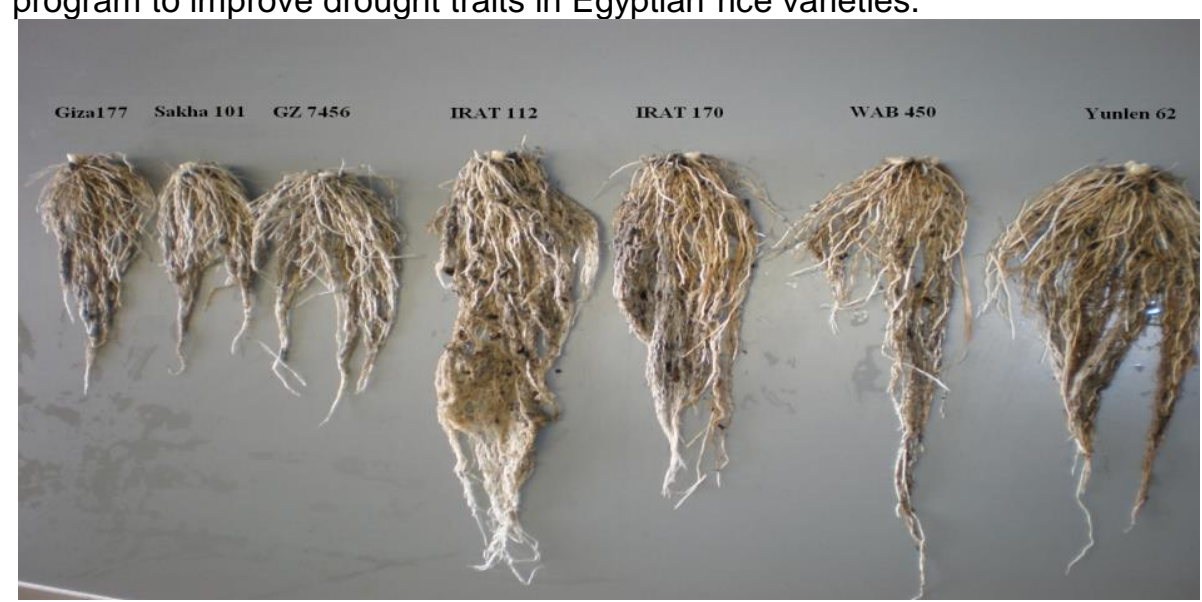

Fig.1: Root morphology for the seven rice genotypes.

\section{Physiological traits:}

Significant variations were found among the genotypes under study for all physiological traits under normal and drought treatments. Regarding to shoot dry weight the upland rice genotypes gave the highest values such as IRAT 170, IRAT 112, Yun Len62 and WAB450-I-B-P-105-HB ( 13.33, 9.27, 9.0 and 8.33 gram, respectively) compared with Giza 177, Sakha 101 and GZ7456-13-6-5-3 which gave the lowest values of 5.43, 7.67 and 6.0 gram, respectively under drought treatment. For days to leaf rolling, it was earlier in Egyptian rice varieties after 11 to 14 days from drought treatment, indicating that these varieties are sensitive to drought condition compared with the upland accessions which were tolerance to drought as it keep water in the leaves under water stress. Also, more than $20 \%$ of leaf area became drying under drought treatment in Egyptian varieties, therefore days to leaf rolling and leaf drying could be used as a score for indicator for sensitive to drought. Mean plant height was reduced under water stress in all genotypes, but the reduction in Egyptian rice varieties more than the reduction in upland rice, for example, Giza 177, Sakha 101 and GZ7456-13-6-5-3 were reduced by 21, 27.7 and $31 \mathrm{~cm}$, respectively, while, the Upland rice IRAT 112, IRAT170, WAB450-I-B-P-105-HB and Yun Len62 recorded the lowest reduction 8, 7, 4.4 and $5.4 \mathrm{~cm}$. For tillers plant ${ }^{-1}$ after 45 days there are significant difference among all genotypes under control and water stress, Yulen62 gave the highest value 8.3 while, Giza 177 gave the lowest one 5. Concerning to flag leaf area, it was reduced in all genotypes under water stress. The reduction in flag leaf area was higher in Egyptian rice varieties, and the reduction was 
more than $50 \%$ of flag leaf area in Egyptian rice varieties compared with upland rice accessions. However, mean heading date was delayed by more than 8 days for all genotypes under water stress.

From the above results, the use of days to leaf rolling, leaf drying score (related to fitness and water status in leaf), reduction in plant height and flag leaf area as indicator for sensitivity to drought, therefore the upland rice accession which have good physiological traits related to fitness could be used in breeding program as donors to improve these traits in Egyptian rice varieties to produce the new lines resistance to drought in Egypt.

Table 2. Means for physiological traits of some Egyptian and upland rice accessions.

\begin{tabular}{|c|c|c|c|c|c|c|}
\hline \multirow[t]{2}{*}{ Entry } & \multicolumn{2}{|c|}{$\begin{array}{c}\text { Tillers plant } \\
\text { days }\end{array}$} & \multicolumn{2}{|c|}{$\begin{array}{l}\text { Days to leaf } \\
\text { rolling }\end{array}$} & \multicolumn{2}{|c|}{ Leaf drying score } \\
\hline & Control & Drought & Control & Drought & Control & Drought \\
\hline Giza177 & 8.0 & 5.0 & 0 & 13.0 & 0 & 4.00 \\
\hline Sakha101 & 11.0 & 7.0 & 0 & 14.3 & 0 & 3.33 \\
\hline GZ7456 & 13.0 & 8.0 & 0 & 11.0 & 0 & 4.67 \\
\hline IRAT112 & 11.0 & 6.3 & 0 & 18.3 & 0 & 0.13 \\
\hline IRAT170 & 11.0 & 7.3 & 0 & 17.6 & 0 & 0.13 \\
\hline WAB450 & 8.3 & 6.0 & 0 & 19.6 & 0 & 0.13 \\
\hline Yun Len62 & 9.0 & 8.3 & 0 & 14.3 & 0 & 1.33 \\
\hline LS.D.0.05 & 1.67 & 1.48 & - & 1.26 & - & 0.94 \\
\hline \multirow[t]{2}{*}{ Entry } & \multicolumn{2}{|c|}{$\begin{array}{l}\text { Flag leaf area } \\
\text { (cm) }\end{array}$} & \multicolumn{2}{|c|}{ Days to heading } & \multicolumn{2}{|c|}{$\begin{array}{l}\text { Plant height } \\
\text { (cm) }\end{array}$} \\
\hline & Control & Drought & Control & Drought & Control & Drought \\
\hline Giza177 & 34.5 & 18.0 & 95.0 & 104.0 & 98.0 & 77.0 \\
\hline Sakha101 & 39.7 & 19.0 & 107.0 & 118.3 & 90.0 & 62.3 \\
\hline GZ7456 & 36.7 & 16.2 & 99.0 & 109.3 & 96.0 & 65.0 \\
\hline IRAT112 & 67.5 & 58.5 & 109.0 & 120.0 & 103.3 & 95.0 \\
\hline IRAT170 & 64.6 & 56.8 & 106.0 & 114.0 & 104.0 & 97.0 \\
\hline WAB450 & 65.5 & 58.5 & 115.0 & 124.0 & 110.6 & 105.0 \\
\hline Yun Len62 & 48.7 & 42.3 & 110.6 & 119.0 & 105.0 & 99.6 \\
\hline LS.D.0.05 & 2.279 & 1.799 & 2.325 & 2.058 & 2.05 & 2.26 \\
\hline
\end{tabular}

Yield and its components:

Significant variation among all genotypes in yield and its components characters were observed. For panicles plant ${ }^{-1}$ WAB450-I-B-P-105-HB gave the highest value of 12 panicles plant ${ }^{-1}$, while, Giza 177 and GZ7456-13-6-53 gave the lowest values of 9 panicles plant $^{-1}$ under water stress. Water stress caused significant reduction in panicle length and filled grains panicle ${ }^{-1}$ for Egyptian rice varieties more than the reduction in upland rice accessions which were less affected by water stress, On the other hand, 1000-grain weight was less affected by drought treatment in all genotypes. Concerning to grain yield $^{-1}$ plant, the water stress caused an average reduction about $50 \%$ of in Egyptian rice varieties (Giza 177, Sakha 101 and GZ7456-13-6-5-3) compared with upland rice accessions, indicating that the Egyptian rice varieties are sensitive to drought, while the upland rice accessions are tolerant to drought, thus could use the upland rice in breeding program to improve these traits in Egyptian rice varieties. 
Table3. Means for yield and its components of some Egyptian and upland rice accessions.

\begin{tabular}{|c|c|c|c|c|c|c|c|c|c|c|}
\hline \multirow[t]{2}{*}{ Entry } & \multicolumn{2}{|c|}{ Panicles plant $^{-1}$} & \multicolumn{2}{|c|}{$\begin{array}{c}\text { 1000-grain } \\
\text { weight } \\
\text { (gm) }\end{array}$} & \multicolumn{2}{|c|}{$\begin{array}{l}\text { Filled grains } \\
\text { panicle }^{-1}\end{array}$} & \multicolumn{2}{|c|}{$\begin{array}{l}\text { Panicle length } \\
\text { (cm) }\end{array}$} & \multicolumn{2}{|c|}{$\begin{array}{c}\text { Grain yield plant } \\
(\mathrm{gm})\end{array}$} \\
\hline & Control & Drought & Control & Drought & Control & Drought & Control & Drought & Control & Drought \\
\hline Giza177 & 15.0 & 9.0 & 27.7 & 24.8 & 134.3 & 78.6 & 23.8 & 15.5 & 39.0 & 21.6 \\
\hline Sakha101 & 18.0 & 11.0 & 27.6 & 25.5 & 163.0 & 126.3 & 25.0 & 20.2 & 44.0 & 28.6 \\
\hline GZ7456 & 16.0 & 9.0 & 28.3 & 25.6 & 154.3 & 106.0 & 25.0 & 18.9 & 40.6 & 24.6 \\
\hline IRAT112 & 14.0 & 11.0 & 30.2 & 29.2 & 163.6 & 146.6 & 27.4 & 24.4 & 44.6 & 41.0 \\
\hline IRAT170 & 14.0 & 11.6 & 30.3 & 28.8 & 177.0 & 154.3 & 27.0 & 24.3 & 46.0 & 42.0 \\
\hline WAB450 & 15.0 & 12.0 & 28.1 & 27.5 & 177.6 & 160.3 & 27.6 & 25.9 & 49.0 & 44.0 \\
\hline Yun Len62 & 17.0 & 11.6 & 23.3 & 22.5 & 145.0 & 131.3 & 23.5 & 22.6 & 40.3 & 35.0 \\
\hline LS.D.0.05 & 1.75 & 1.58 & 0.94 & 0.58 & 6.89 & 5.96 & 0.88 & 0.90 & 2.20 & 1.99 \\
\hline
\end{tabular}

\section{Genetic relationships and clustering of genotypes:}

Genetic relationships among the rice genotypes are shown in Fig 2. Rice genotypes clustered into three principal groups based on SSR markars data. Group 1 contained the Egyptian rice varieties, Giza 177, Sakha 101 and GZ7456-13-6-5-3, indicating that the highest similarity among them. These results are in agreement with the genetic background of Giza 177, Sakha 101 and GZ7456-13-6-5-3. Group 2 included WAB450-I-B-P-105-HB and Yun Len62 there are similarity among Egyptian rice varieties and WAB450-I-B-P105-HB and Yun Len62 (0.545). While, the group3 contained the upland rice varieties from Cote de Ivoire IRAT 112and IRAT170 recorded the lowest similarity with Egyptian rice varieties (0.117). The grouping of rice varieties through molecular markers was performed according to their geographic origins and pedigree of the genotypes.

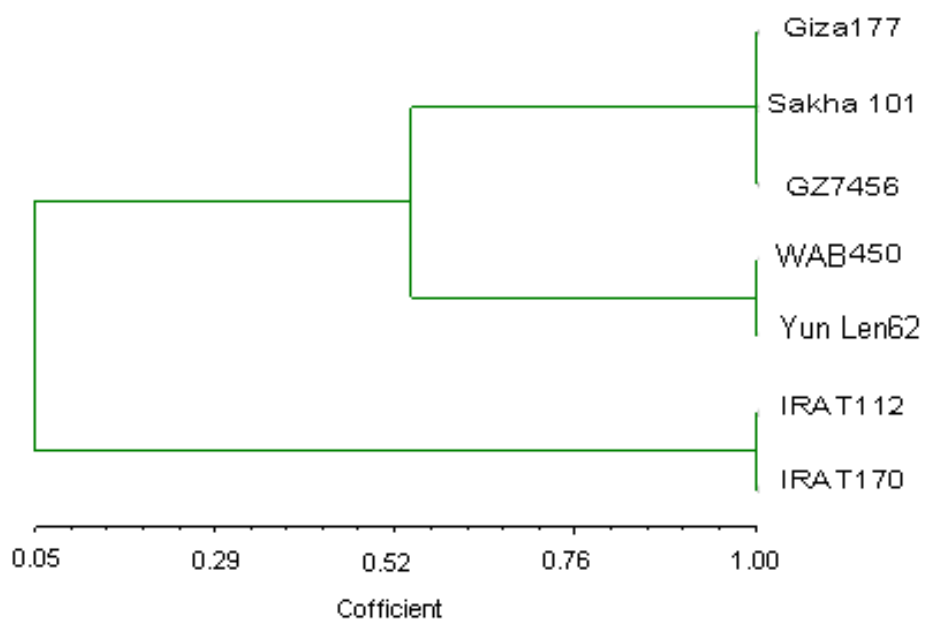

Fig.2: Clustering of seven rice genotypes based on pooled SSR markers. 
From the above results, the molecular characterization using SSR markers show the genetic relationship among the genotypes under this study, indicating that there are genetic diversity among the genotypes used.

RM283

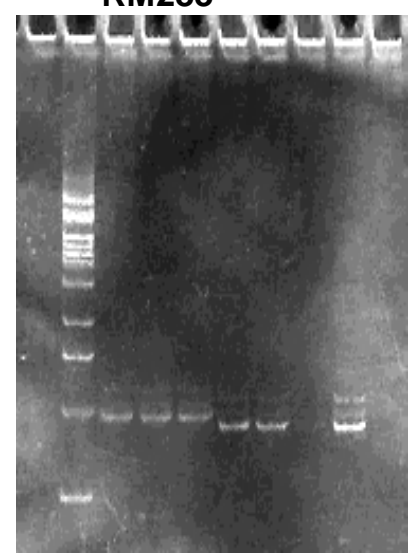

RM3335

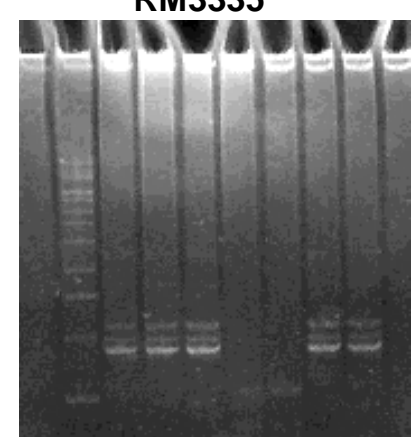

RM495

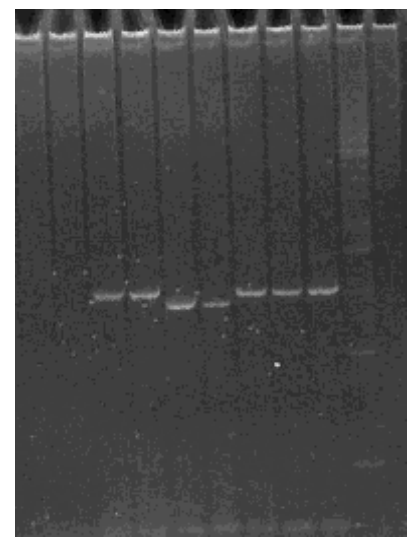

RM3311

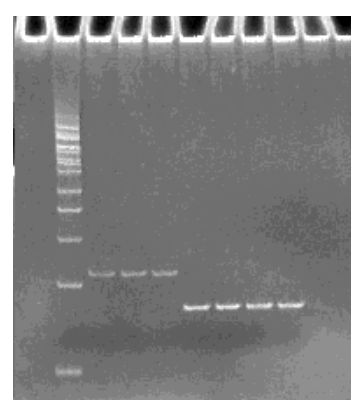

Fig 3: Four examples of SSR markers detected by primers RM 283, 495, 3335 and 7575 among 7 rice genotypes from 1 to 7 : Giza 177, Sakha 101, GZ7456-13-6-5-3, IRAT 112, IRAT 170, WAB450-I-B-P105-HB and Yun Len62.M: DNA ladder marker (50bp).

Relationships depending on 17 morphological traits illustrated in Fig 4. Rice genotypes clustered into three principal groups based on morphological data. Group1 contained the Egyptian varieties, Giza 177, Sakha 101 and GZ7456-13-6-5-3, indicating that the highest similarity in morphological traits among them, While, group 2 included IRAT 112 and IRAT 170 upland rice accessions and there are similarity among these accession and WAB450-I-B-P-105-HB in morphological traits while, Yun Len62 located alone in the third group. 


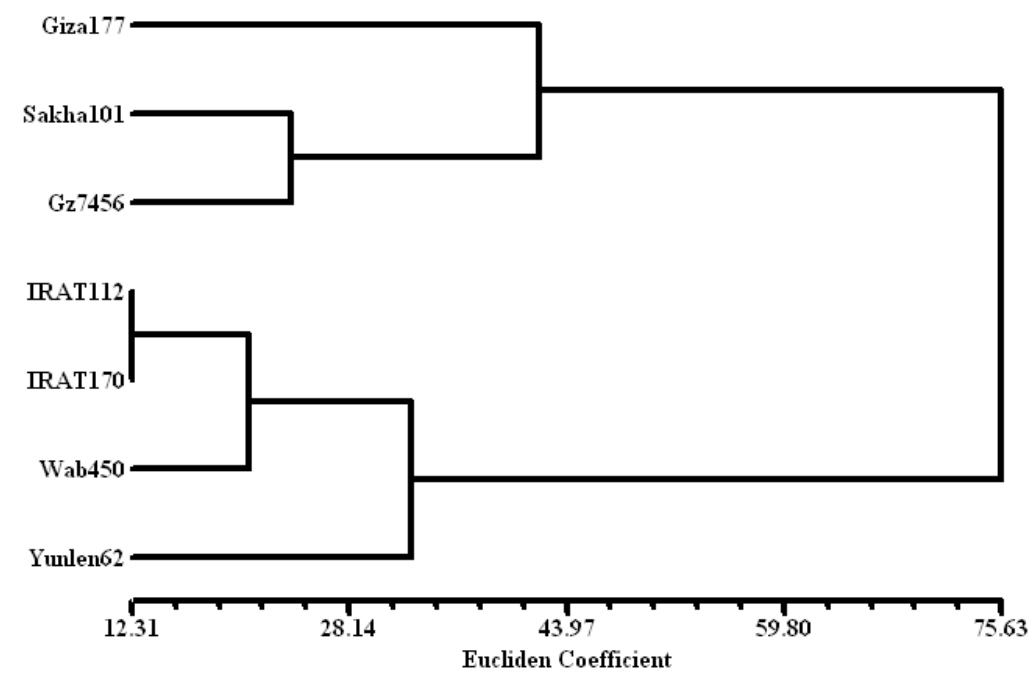

Fig.4: Clustering of seven rice genotypes based on 17 morphological traits.

\section{Genetic parameters:}

Phenotypic and genotypic coefficients of variability, heritability and genetic advance from selection for each trait are presented in Table 4 . The rice varieties showed a wide range of variation for all studied traits, where mean squares for all traits were highly significant. Thus, selection for these traits among these varieties would be effective in all cases. Similar results were obtained by Aly and Shaalan (1984). The genetic coefficient of variability (G.C.V) for some of root traits, physiological and yield and its components characters and ranged between 28.22 and $325.54 \%$ respectively. The relatively high genetic coefficient of variability for root, physiological traits and yield and its components indicated that these traits might be more genotypically predominant and it would be possible to achieve further improvement in them. However, the phenotypic coefficient of variability was higher than the genotypic one in all studied characters, but the most portion of P.C.V was contributed by the genotypic component, less by environmental component.

Estimates of heritability in broad sense were high for all studied traits and ranged between 61 and 99\% (Table 4). High heritability estimates are useful while, making selection based on phenotype. High heritability values coupled with high genetic advance percentage (Table, 4) were observed for root morphology traits, shoot dry weight, leaf drying score, flag leaf area and grain yield plant ${ }^{-1}$. This indicate that selection process for these traits would certainly bring improvement in the genotypes. Burton (1952) reported that genotypic coefficient of variability, together with heritability estimates would give a clear picture about the extent of advance to be expected from selection, therefore the expected gain from selection $(\Delta \mathrm{g} \%)$ would be a better 
indicator for selection response. With regard to Burton (1952), all the studied traits showed relatively high G.C.V with high heritability estimates in broad sense. Accordingly, the expected genetic advance $(\Delta g \%)$ from selection appeared to be effective for these traits. In conclusion, genetic improvement would be feasible among the tested genetic background for further enhancement of such root, physiological traits which decimally results in a higher yield potential.

Table 4. Estimates of phenotypic and genotypic coefficients of variability, heritability and expected genetic advance for17 traits in seven genotypes of rice (Oryza Sativa L.) under drought condition.

\begin{tabular}{|c|c|c|c|c|c|c|c|c|c|c|}
\hline \multirow[b]{2}{*}{ Characters } & \multicolumn{10}{|c|}{ Parameters } \\
\hline & Means & $\begin{array}{c}\text { Ms } \\
\text { genotype }\end{array}$ & Error & ph & g & G.C.V & P.C.V & $\begin{array}{l}\text { Herita- } \\
\text { bility }\end{array}$ & $\Delta \mathrm{G}$ & $\Delta \mathrm{G} \%$ \\
\hline Root length & 27.14 & 150.59 & 0.5667 & 50.56 & 50.0 & 135.73 & 136.48 & 0.98 & 14.35 & 52.87 \\
\hline Root volume & 37.18 & 2.39 & 491 & 147.78 & 147.29 & 199.0 & 199.36 & 0.99 & 24.77 & 66.62 \\
\hline Root thickness & 0.866 & 0.2160 & 0.0061 & 0.0751 & 0.069 & 28.22 & 29.44 & 0.92 & 0.511 & 59.0 \\
\hline Root dry weight & 3.98 & 3.524 & 0.0057 & 1.177 & 1.172 & 54.26 & 54.38 & 0.99 & 2.20 & 55.27 \\
\hline Root/shoot ratio & 0.4846 & 0.02922 & 0.000033 & 0.00977 & 0.00973 & 14.16 & 14.19 & 0.99 & 0.199 & 41.1 \\
\hline Shoot dry weight & 8.43 & 20.266 & 0.0034 & 6.757 & 6.754 & 89.5 & 89.52 & 0.99 & 5.28 & 62.63 \\
\hline Tillers plant $^{-1}$ & 6.84 & 4.048 & 0.671 & 1.79 & 1.12 & 40.46 & 51.15 & 0.62 & 1.69 & 24.70 \\
\hline Days to leaf rolling & 15.44 & 29.208 & 236 & 9.88 & 9.65 & 79.10 & 79.99 & 0.97 & 6.27 & 40.60 \\
\hline Leaf dry & 1.96 & 11.91 & 0.0015 & 3.962 & 3.96 & 142.14 & 142.17 & 0.99 & 4.05 & 206.6 \\
\hline Flag le & 38.45 & 1223.505 & & 408.53 & 407.48 & 325.54 & 325.95 & 0.99 & 41.21 & 107.17 \\
\hline Days to & 115.5 & 142.65 & 381 & 48.47 & 47.09 & 63.85 & 64.78 & 0.97 & 13.90 & 12.03 \\
\hline Plant height & 85.84 & 915.73 & 0.812 & 305.78 & 304.97 & 188.48 & 188.73 & 0.99 & 35.64 & 41.52 \\
\hline Panicles plant $^{-1}$ & 10.74 & 4.628 & 0.812 & 2.084 & 1.272 & 34.41 & 44.10 & 0.61 & 1.81 & 16.85 \\
\hline 1000-grain weight & 26.28 & 16.85 & 0.3 & 5.83 & 5.50 & 45.74 & 47.10 & 0.94 & 4.66 & 17.73 \\
\hline $\begin{array}{l}\text { Filled grains } \\
\text { panicle }^{-1}\end{array}$ & 129.10 & 2505.3 & 11.57 & 842.81 & 831.24 & 253.74 & 255.50 & 0.98 & 58.6 & 45.39 \\
\hline Panicle & 21.69 & 40.62 & & 13.72 & 13.45 & 78.74 & 79.53 & 0.98 & 7.46 & 34.39 \\
\hline Grain yield plant $^{-1}$ & 33.85 & 240.76 & 1.28 & 81.10 & 79.82 & 153.55 & 154.78 & 0.98 & 18.16 & 53.64 \\
\hline
\end{tabular}

\section{Correlation coefficient:}

The relationships among the studied traits represented as correlation coefficient are presented in Table 5. The correlation coefficient was statistically estimated as reported by Gomez and Gomez (1983). Significant and highly significant positive correlations were observed between root length and each of root volume, root dry weight and root thickness $(0.989,0.99$ and 0.748 , respectively).

Correlation coefficient between root traits and some physiological traits is concern significant and highly significant positive correlations were found among root traits (root length, root volume, root dry weight and root thickness) and flag leaf area, days to leaf rolling and plant height. Also, there are significant and highly significant positive correlations among days to leaf rolling and each of flag leaf area and plant height. On the other hand, significant and highly significant negative correlations values were found among root traits and leaf drying score.

Concerning to correlation coefficient between root traits and yield and its components, significant and highly significant positive correlations were found among root traits (root length, root volume, root thickness and root dry weight) and yield and its components traits. 
Sedeek, S. E. M. et al.

5

152 
The significant correlations among most of the root traits which observed in this investigation indicated that these traits are interrelated together. Similar results were also reported by Champoux et al., 1995, Thanh et al., 1999. Maximum root length, root volume, root thickness and root dry weight are believed to play a significant role in drought resistance mechanism (avoidance method) by absorbing greater amount of water from lower soil layers. Since the root traits were found to be positively correlated. Moreover, the selection based on any of the root traits especially the easily measurable one, as for example, root thickness may provide breeders an opportunity to develop drought resistant in Egyptian rice varieties. Further studies using molecular mapping tools would be needed to determine the genetic basis of these associations.

\section{CONCLUSION}

The data showed significant variation in root morpho-physiological traits and microsatellite DNA polymorphisms among Egyptian rice varieties and upland rice accessions under normal and drought condition. The upland rice accession resistant to drought because they have good root system (drought avoidance), while, the Egyptian rice varieties are sensitive to drought, so could use the upland rice accessions in breeding program to transfer the genes which responsible to drought tolerance into Egyptian rice varieties. Molecular markers especially SSR markers are the most efficient source of diversity studies in crop species.

\section{REFERENCES}

Allard, R.W. (1960). Principles of plant breeding. John Wiley and Sons Inc. N. Y, USA. pp. 485.

Aly, A.E.; M.I. Shaalan and M.A. Shaalan (1984). Phenotypic and genotypic varaiability in some local and introduced rice cultivars and strains (Oryza Sativa L.). Alex. J. Agric. Res. 29: 97-103.

Burton, G.W. (1952). Quantitative inheritance in grasses. Proc. Sixth Inter. Grassland Cong 1: 277-283.

Champoux,M.C., G. Wang, S. Sarkanung, D.J. Mackill, J.C. Otoole, N. Huang and S.R. Mc Couch (1995). Locating genes associated with root morphology and drought avoidance in rice via linkage to molecular markers. Theor.APPL.Genet.90:969-981.

Dice LR (1945). Measures of the amount of ecologic association between species. Ecology 26:297-302.

Fukai, S. and M. Cooper (1995). Development of drought resistant cultivars using Physio-morphological traits in rice. Field Crops Res.40:67-86.

Gamble, E. E. (1962). Gene effects in corn " Zea mays L." 1- separation and relative importance of gene effects for yield. Con. J. of Plant Sci. 42: 339-348.

Gomez,K.A. and A.A. Gomez (1983). Statically procedures for agricultural research. Second Edition.680P.

Gupta,P.K., H.S. Balyan, P.C. Sharma and B. Ramesh (1996). Microsatellites in plants: a new class of molecular markers. Curr.Sci.70, 45-54. 
Kamoshita, A.; J. Wade; L. Ali; S. Pathan; and J. Zhang (2002). Mapping QTLs for root morphology of a rice population adapted to rainfed lowland conditions. Theor. Appl. Genet.104:880-893.

Kato.Y; A. Kamoshita; J.Yamagishi; H. Imoto and J. Abe (2007). Growth of rice (Oryza sativa $L$.) cultivars under upland conditions with different levels of water supply. 3 - root system development, water extractions and plant water status. Plant Prod. Sci. 10:3-13.

Khush: G.S. (2005). What it will take to feed 5.0 Billion Rice consumers in 2030. Plant Molecular Biology 59:1-6.

Lilley, J.M. and S. Fukai (1994). Effect of timing and severity of water deficition four diverse rice cultivars. I. Rooting pattern and soil water extraction. Field Crops Res. 37: 205-213.

Lilley; J.M., M. Ludlow; S.Mccouch and J.C. OToole (1996). Location QTL for osmotic adjustment and dehydration tolerance in rice. J. Exp. Bot.47:1427-1436.

Ludlow, M.M. and R.C. Muchow (1990). Acritical evalution of traits for improving crop yields in water limited environments. Adv. Agron. 43:107-153.

Murray,M.G. and W.F. Thompson (1980). Rapid isolation of high molecular weight plant DNA. Nucleic Acids Res.8: 4321-4325.

Neguen,H.T., R.C.Babu and A.Blum (1997). Breeding for drought resistance in rice. Physiology and molecular genetics considerations. Crop Sci. 37:1426-1434.

Nei Mand and Li WH (1979).Mathematical model for studying genetic variation in terms of restriction end nucleases. Proc.Natl acad Sci USA 76:5269-5273.

Nemoto, H.; R. Suga; M. Ishihara and Y. Okutsu (1998). Deep root rice varieties detected through the observation of root characteristics using the trench method. Breed Sci. 48:321-324.

Paterson, A.H., S.D. Tanksley and M.E. Sorrels (1991). DNA markers in plant improvement. Adv. Agronomy 46:39-90.

Robin, S.; M.S. Pathan; B. Courtois; R. Lafitte; S. Carandang (2003). Mapping osmotic adjustment in an advaced back-cross inbred population of rice. Theor. Appl.Genet. 107:1288-1296.

Rohlf,J. (2000). Numerical taxonomy and multivarieties analysis system NTSYS-PC.version 2Exeter software,New York.

Siopongco, J.DL.c; A. Yamauchi; H. Salekdeh; J. Bennett and L.J. Wade (2005). Root growth and water extraction response of double haploid rice lines to drought and rewatering during the vegetative stage. Plant Prod. Sci.9:497-508.

Tanksley, S.D., A.H. Young, A.H. Paterson and M.W. Bomerbale (1989). RFLP mapping in plant breeding: New tool for an old science. Theor APPL Gent 75:257-264.

Thanh,N.D.,H.G. Zheng, N.V. Dong, L.N. Trinh, M.L. Ali and H.T. Nguyen (1999). Genetic variation in root morphology and microsatellite DNA loci in upland rice (Oryza sative L.) from Vietnam. Euphytica,105:4351. 
Tripathy, J.N.; J. Zhang; S. Robin and H.T. Nguyen (2000). QTLs for cellmembrane stability mapped in rice (Oryza sativa L.) under drought stress. Theor. Appl. Genet.100:1197-1202.

Wunsch,A. and J.I. Hormaza (2002).Cultivar identification and genetic fingerprinting of temperate fruit tree species using DNA markers. Euphytica 125,56-67.

Zhang, J.; H.T. Nguyen and A. Blum (1999). Genetic analysis of osmotic adjustment in crop plants. J. Exp. Bot: 291-302.

Zhang; J., H.G. Zheng, A.Aarti; G. Pantuwan; T.T. Nguyen (2001). Locating genomic regions associated with components of drought resistance in rice: comparative mapping within and across species. Theor. Appl.Genet.103:19-29.

Zheng, B.S.; L. Yang; W.P. Zhang; C.Z. Mao; Y.R. Wu; K.K. Yi; F.Y. Liu and P. Wu (2003). Mapping QTLs and candidate genes for rice root traits under different water supply conditions and comparative analysis across three populations. Theor Appl. Genet 107:1505-1515.

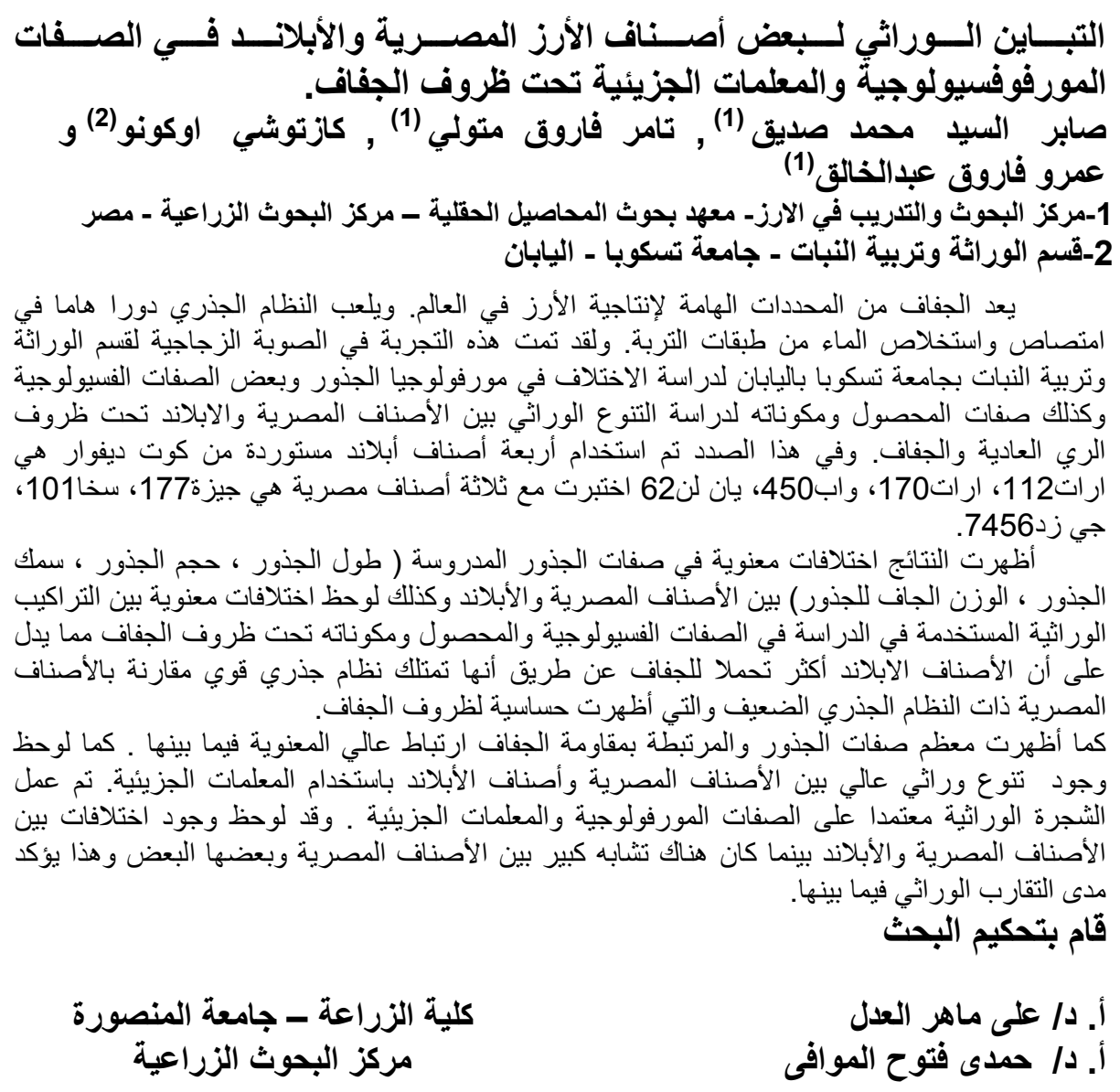


Sedeek, S. E. M. et al. 
J. of Agricultural Chemistry and Biotechnology, Vol. 1 (3), March, 2010 

Table 5. Correlation coefficient among some of root traits, physiological traits and yield and its components.

\begin{tabular}{|c|c|c|c|c|c|c|c|c|c|c|c|c|c|c|c|c|}
\hline & RV & RT & RDW & RSR & SDW & Tillers & DTLR & LDS & FLA & HD & PH & $\mathbf{P} / \mathbf{P}$ & 1000 & FG/P & PL & GY \\
\hline $\mathrm{RL}$ & $.98^{* *}$ & .75 & $.99^{* *}$ & .36 & .64 & -.16 & $.95^{\star *}$ & -.98 & $.97^{\star *}$ & .75 & $.91^{* *}$ & $.82^{*}$ & .54 & $.85^{*}$ & $.90^{* *}$ & $.95^{\star \star}$ \\
\hline $\mathrm{RV}$ & & .66 & $.97^{* *}$ & .44 & .57 & -.14 & $.94^{* *}$ & $-.93^{* *}$ & $.95^{\star *}$ & $.77^{\star}$ & $.90^{\star *}$ & $.80^{*}$ & .53 & $.86^{*}$ & $.91^{* *}$ & $.95^{\star *}$ \\
\hline RT & & & $.82^{*}$ & .04 & .68 & .35 & .59 & $-.82^{*}$ & $.79^{*}$ & .67 & .73 & .74 & .22 & .71 & $.77^{*}$ & $.76^{*}$ \\
\hline RDW & & & & .37 & .64 & -.04 & $.90^{* *}$ & $-.97^{* *}$ & $.98^{\star *}$ & $.76^{\star}$ & $.93^{\star *}$ & $.81^{*}$ & .48 & $.85^{\star}$ & $.91^{* *}$ & $.95^{\star *}$ \\
\hline RSR & & & & & -.47 & -.49 & .28 & -.16 & .22 & .26 & .37 & -.01 & -.02 & .01 & .13 & .14 \\
\hline SDW & & & & & & .29 & .64 & $-.79^{*}$ & .75 & .42 & .60 & .73 & .52 & $.77^{\star}$ & .73 & $.78^{*}$ \\
\hline Tillers & & & & & & & -.30 & .03 & -.04 & .19 & -.06 & .19 & -.31 & .22 & .21 & .06 \\
\hline DTLR & & & & & & & & $-.93^{\star *}$ & $.92^{\star *}$ & .72 & $.78^{*}$ & $.80^{*}$ & .69 & $.85^{\star}$ & $.86^{*}$ & $.93^{\star *}$ \\
\hline LDS & & & & & & & & & $-.99^{* *}$ & -.72 & $-.90^{\star *}$ & $-.86^{*}$ & -.55 & $-.89^{* *}$ & $-.92^{* *}$ & $-.97^{* *}$ \\
\hline FLA & & & & & & & & & & .68 & $.91^{\star *}$ & $.79^{\star}$ & .61 & $.87^{*}$ & $.92^{\star \star}$ & $.97^{* *}$ \\
\hline HD & & & & & & & & & & & .55 & $.88^{\star \star}$ & .26 & $.86^{*}$ & $.87^{*}$ & $.79^{*}$ \\
\hline $\mathrm{PH}$ & & & & & & & & & & & & .72 & .29 & .68 & $.77^{*}$ & $.84^{*}$ \\
\hline$P / P$ & & & & & & & & & & & & & .27 & $.90^{\star *}$ & $.89^{* *}$ & $.88^{\star *}$ \\
\hline 1000 & & & & & & & & & & & & & & .58 & .54 & .61 \\
\hline FG/P & & & & & & & & & & & & & & & $.99^{* *}$ & $.96^{\star *}$ \\
\hline $\begin{array}{l}P L \\
G Y\end{array}$ & & & & & & & & & & & & & & & & $.98^{* \star}$ \\
\hline & & & & & & & & & & & & & & & & \\
\hline
\end{tabular}

${ }^{*}$ correlation is significant at the 0.05 level (2- tailed).

** Correlation is significant at the 0.01 level (2- tailed).

${ }^{* \star}$ Correlation is significant at the 0.01 level (2- tailed).
RL: root length

RSR: root/shoot ratio

RV: root volume

LDS: leaf drying score

FLA: flag leaf area

RT: root thickness

Tillers: tillers plant

RDW: root dry weight

P/P: panicles plant ${ }^{-1}$

1000: 1000-grain weight

HD: days to heading

DTLR: days to leaf rolling

PH: plant height

GY: grain yieldplant

FG/P: filled grains panicle ${ }^{-1}$

PL: panicle length 